\title{
Digestion of starch and crude fibre in segments of the digestive tract of sheep fed different types and amounts of starch
}

\author{
B. Kowalik ${ }^{1}$, J. Kowalczyk, J.J. Pająk and T. Żebrowska \\ The Kielanowski Institute of Animal Physiology and Nutrition, \\ Polish Academy of Sciences \\ 05-110 Jabłonna, Poland
}

\begin{abstract}
The experiment was carried out on 6 Polish Merino sheep of average $60 \mathrm{~kg} \mathrm{BW}$ with reentrant cannulas into the proximal duodenum and terminal ileum. The animals were fed a basic diet consisting of meadow hay and rapeseed oilmeal with the addition of 46 or $23 \%$ of potato, maize, or wheat starch. The amount of digesta entering the duodenum and large intestine was measured, sampled and the amount of starch and crude fibre determined. All types of starch were digested predominantly in the rumen. Of every $100 \mathrm{~g}$ of starch ingested with the high- (or low-, in parenthesis) starch diet, its output from the rumen was: 10.4, 3.3 and 9.6 (15.2, 8.2 and 11.3) $\mathrm{g}$; from the small intestine, 5.3, 0.7, and $2.7(5.0,1.9$, and 3.2) g; excreted with faeces $1.1,0.3$ and $0.3(0.4$, 0.2 and 0.3$) \mathrm{g}$, of potato, maize or wheat starch, respectively. Maize and wheat starch were more susceptible to digestion in the rumen and small intestine than potato starch. Only a small amount of starch reached the large intestine where it was nearly totally digested and only its traces were excreted with faeces. A higher ratio of starch to crude fibre in the diet depressed crude fibre digestion in the rumen and its total digestibility in the digetsive tract.
\end{abstract}

KEY WORDS: starch, nutrient, digestibility, digestive tract segments, sheep

\section{INTRODUCTION}

Starch in the diet for ruminants affects nutrient digestion processes, bacterial protein synthesis, and dietary nitrogen utilization. High levels of starch in the diet usually decrease structural fibre digestibility due to the rapid fermentation of starch to volatile fatty acids that decrease the $\mathrm{pH}$ and cellulolytic enzyme activity in the rumen. The disappearance rate of starch in the rumen depends on the amount of

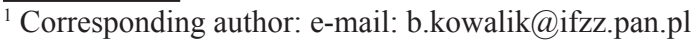


starch ingested, rate of ruminal digesta output, and the origin of the starch. According to literature data, cereal starch is fermented more easily in the rumen than starch of maize, sorgo, legumes or potatoes (Żebrowska et al., 1997; Mills et al., 1999; Monteils et al., 2002). Data concerning the amount of starch leaving the rumen and entering the further part of the digestive tract and its digestion are scanty.

The aim of the study was to determine the effect of the amount and origin of starch in the diet on nutrient digestion in the rumen, small and large intestines of sheep.

\section{MATERIAL AND METHODS}

The experiment was carried out on 6 Polish Merino sheep of average $60 \mathrm{~kg}$ BW with re-entrant cannulas into the proximal duodenum and terminal ileum, fed a basic diet consisting of meadow hay, rapeseed oilmeal and mineral mixture, and supplemented, instead of hay, with 46 or $23 \%$ of potato, maize or wheat starch for respective groups of animals. The diets were isonitrogenous $(11.5 \%$ crude protein) and contained 12.3 or $11.1 \mathrm{MJ} \mathrm{ME}$, respectively, in the diets with 46 or $23 \%$ of starch. The animals were fed $1.2 \mathrm{~kg}$ /day in two portions at 8.00 and 16.00 at free access to water.

After 14 days of adaptation, faeces was collected for 3 days; duodenal and ileal digesta were collected and sampled from 8.00 to 16.00 and pooled for 3 days.The samples were frozen until analysis for nutrient content (AOAC, 1990).

The obtained results were subjected to statistical analysis of variance according to the Statgraphics ${ }^{\circledR}$ ver.7.0 (1993) procedure.

\section{RESULTS}

The main site of all types of starch digestion was the rumen and in the total digestive tract, starch was digested nearly completely. Of each $100 \mathrm{~g}$ of starch ingested with a high-starch diet, its output (respective data for low level of starch are given in paranthesis) from the rumen was: 10.4, 3.3 and $9.6(15.2,8.2$ and 11.3) $\mathrm{g}$; from the small to large intestine 5.3, 0.7 , and $2.7(5.0,1.9$, and 3.2) $\mathrm{g}$; excreted with faeces $1.1,0.3$ and $0.3(0.4,0.2$ and 0.3$) \mathrm{g}$, respectively, of potato, maize or wheat starch. Ruminal digestibility of starch at a high level of maize in the diet differed $(\mathrm{P}<0.01)$ from that of potato or wheat but there were no differences between starch type fed at low levels $(\mathrm{P}>0.05)$. In the small intestine, both levels of maize starch were digested better than potato starch. In the large intestine, potato and wheat starch were digested better than maize starch. Total digestive tract digestibility did not differ between types and levels of starch except for slightly but significantly higher $(\mathrm{P}<0.05)$ than for potato starch.

Ruminal digestibility of crude fibre when feeding a high potato starch diet was significantly $(\mathrm{P}<0.01)$ higher than at a similar level of wheat starch, but at feeding 
low starch diets, a higher digestibility was obtained for maize starch $(\mathrm{P}<0.01)$. The crude fibre of all diets with a high level of starch was digested worse than in diets containing less starch $(\mathrm{P}<0.01)$. Crude fibre digestibility coefficients in the small intestine did not differ statistically between levels or type of starch $(\mathrm{P}>0.05)$. In the large intestine, crude fibre was digested better when high- than low-starch diets were fed. Total digestive tract crude fibre digestion was the highest when the diet with a low level of maize starch was fed.

Table 1. Starch and crude fibre digestibility (\%) in total, or partial digestive tract in sheep fed different types of starch at high (46\%) or low (23\%) levels in the diet

\begin{tabular}{|c|c|c|c|c|c|c|}
\hline \multirow{2}{*}{ Starch level } & \multicolumn{3}{|c|}{ Starch } & \multicolumn{3}{|c|}{ Crude fibre } \\
\hline & potato & maize & wheat & potato & maize & wheat \\
\hline \multicolumn{7}{|c|}{ Digestibility in the rumen } \\
\hline high & $89.6^{\mathrm{B}}$ & $96.7^{\mathrm{A}}$ & $90.4^{\mathrm{B}}$ & $36.6^{\mathrm{A}}$ & $32.5^{\mathrm{AB}}$ & $21.4^{\mathrm{B}}$ \\
\hline low & 84.8 & 91.8 & 88.7 & $55.3^{\mathrm{AB}}$ & $64.8^{\mathrm{A}}$ & $48.7^{\mathrm{B}}$ \\
\hline \multicolumn{7}{|c|}{ Digestibility in the small intestine } \\
\hline high & $48.8^{\mathrm{A}}$ & $78.7^{\mathrm{B}}$ & $71.4^{\mathrm{B}}$ & 14.8 & 21.2 & 20.1 \\
\hline low & 67.4 & 76.9 & 71.7 & 20.6 & 19.0 & 16.2 \\
\hline \multicolumn{7}{|c|}{ Digestibility in the large intestine } \\
\hline high & $79.7^{\mathrm{A}}$ & $55.9^{\mathrm{B}}$ & $89.0^{\mathrm{B}}$ & 30.5 & 29.0 & 44.1 \\
\hline low & 91.1 & 88.7 & 90.8 & 18.7 & 19.9 & 25.1 \\
\hline \multicolumn{7}{|c|}{ Digestibility in the total digestive tract } \\
\hline high & $99.0^{\mathrm{a}}$ & $99.7^{\mathrm{b}}$ & $99.8^{\mathrm{b}}$ & 62.5 & 62.3 & 62.2 \\
\hline low & 99.7 & 99.8 & 99.7 & $71.3^{\mathrm{AB}}$ & $77.2^{\mathrm{A}}$ & $68.0^{\mathrm{B}}$ \\
\hline
\end{tabular}

\section{DISCUSSION}

The results demonstrate that the main site of starch digestion, independently of its type and content in the diet, is the rumen where about $90 \%$ of dietary starch is fermented. However, potato starch appeared more resistant to decomposition in the rumen than maize or wheat starch, of which only a small proportion reached the duodenum. It confirms that bacterial $\alpha$-amylase excreted by Clostridium butiricum or Streptococcus bovis hydrolyses potato starch slowly, but extracellular $\alpha$-amylase is not able to hydrolyse this type of starch. The reason for the lower digestibility in the low-starch diets could be explained by the changed diet composition, as in this case the fibre content was significantly higher and cellulytic enzyme activity prevailed over amylolytic activity. The digestibility coefficient of all types of starch in the small intestine was lower than in the rumen as the digesta in the small intestine does not contain developed amylotylic microorganisms. However, maize and wheat starch was, similarly as in the rumen, 
more susceptible to digestion in the small intestine than potato starch, particularly when fed in larger amounts. Only a small amount of starch reached the large intestine where conditions for its digestion were similar to those in the rumen. Only about $1 \%$ of ingested starch, including potato starch, avoided fermentation in the large intestine and was excreted in faeces.

Better digestion of crude fibre in the rumen when a diet with a high level of potato starch was fed can be explained by the lower fermentation of potato starch leading to fewer volatile fatty acids and a higher $\mathrm{pH}$ in the rumen, creating better conditions for development of fibrolytic bacteria. Feeding the diets with high levels of all types of starch significantly depressed fibre digestibility compared with results obtained on low-starch diets. Digestion of fibre reaching the small intestine was low, demonstrating low fibrolytic activity of small intestine digesta. Differences in fibre digestion in the large intestine of animals fed different types of starch were not significant and should be attributed to differentiated levels of fibre in the diet and low digestibility of fibre in the rumen of animals fed high levels of starch. As a result, total digestibility of crude fibre was not affected by the type of starch fed but a lower ratio of starch to crude fibre in the diet stimulated fibre digestion.

\section{CONCLUSIONS}

Potato, maize and wheat starch in diets fed to sheep are digested predominantly in the rumen and only a small percentage of ingested starch reaches the small intestine where the rate of its digestion is lower than in the rumen. Maize and wheat starch are more susceptible to digestion in the rumen and small intestine than potato starch. Only a small amount of starch reaches the large intestine where it is nearly totally digested and only traces are excreted with faeces. A higher ratio of starch to crude fibre in the diet depresses crude fibre digestion in the rumen and its digestibility in the total digetsive tract.

\section{REFERENCES}

AOAC, 1990. Official Methods of Analysis, Association of Official Analytical Chemists. $15^{\text {th }}$ Edition. Arlington, VA

Mills J.A.N., France J., Dijkstra J., 1999. A review of starch digestion in the lactating dairy cows and proposals for a mechanistic model: 1. Dietary starch characterisation and ruminal starch digestion. J. Anim. Feed Sci. 8, 291-340

Mills J.A.N., France J., Dijkstra J., 1999. A review of starch digestion in the lactating dairy cows and proposals for a mechanistic model: 2. Postruminal digestion and small intestinal glucose absorption. J. Anim. Feed Sci. 8, 451-481

Monteils U., Jurjanz S., Colin-Schoellen O., Blanchart G., Laurent F., 2002. Kinetics of ruminal digestion of wheat and potato starches in total mixed rations. J. Anim. Sci. 80, 235-241

Żebrowska T., Długołęcka Z., Pająk J.J., Korczyński W., 1997. Rumen degradability of concentrate protein, amino acid and starch and their digestibility in the small intestine of cows. J. Anim. Feed Sci. 10, 619-626 